\title{
SOME GOVERNING PRINCIPLES OF THE RECOVERY WARD
}

\author{
By Russell M. Davies, F.F.A., R.C.S. \\ Consultant Anaesthetist, Queen Victoria Hospital, East Grinstead
}

John Snow (1858) suggested that a room might be set aside in which the patient who has undergone surgery and anaesthesia could recover under skilled care and free from outside disturbance. For almost a century no action seems to have been taken on this advice, but in the last 15 years reports have been appearing urging the advantages of these wards, now dealing with very large numbers of patients. Various reports in the Proceedings of the Mayo Clinic comment on the post-operative management of over 20,000 patients: Lowenthal and Russell (195I) reported on the management of 35,000 patients; Davies and Hunter (1952), 13,000 cases.

From these and other reports it would appear that a large proportion of post-operative disasters now having a fatal outcome could in future be avoided if the post-operative period were constantly supervised by a nursing team with specialized experience, and it is quite apparent throughout all these writings that the dominant theme is the life-saving effect of these wards.

We previously reported (Davies and Hunter, 1952) on the planning and use of a recovery ward (with ro beds in ro rooms) which was opened at the Queen Victoria Hospital, East Grinstead, in February 1946. During its first II years 29,388 patients have been nursed on their reception from the operating theatres. As a result of this experience we now feel that certain principles should govern the working of these wards. These principles (some of which are now generally recognized) are discussed in detail below. The list may not be comprehensive, but contains our more definitely crystallized thoughts on this subject.

I. The ward must be staffed for 24 hours a day. Not all such wards are so staffed. For example, the recovery wards (or post-anaesthetic rooms as they are called) at St. Mary's Hospital in Rochester, Minnesota, are open from 9 a.m. to 5 p.m. Under such an arrangement if a patient returns from operation after 5 p.m. it is not possible to offer them the advantages and skill of recovery ward care. Also deprived of these benefits is the surgical emergency operated upon outside " normal working hours.' It would be logical to staff such a ward by nursing shifts. Where the hospital operates two daily shifts of nurses the ward might be opened for approximately 12 to 13 hours, e.g. 7.30 a.m. to 8.30 p.m. as a maximum. Where the hospital operates the three-shift day the ward would be open for eight or 16 hours. Either of these arrangements, however, may deprive the often needy emergency case of special care. It is our experience that it has proved easier to plan the ward staffing in the same way as that of any other ward. In the case of our own ward the normal day and night staffing arrangements are followed, the ward having the status of a special department in the hospital and being staffed for 24 hours a day. The work load being lighter at the weekend, there is a tendency to arrange 'days off' at this time. This arrangement has its attractions.

In accordance with the parallel between this ward and any other, there is a sister or charge nurse in charge. The nursing administration comes directly under the care of the matron, and not under that of the theatre sister or any other departmental sister. The nursing staff's sole duty is to care for the patient in the post-operative period, and they can thus develop interests and skills more single-mindedly than if their appointment was a joint one to two units in the hospital.

2. All patients who have had general anaesthesia should pass through the ward. Any other procedure involves guessing or prophecy of the patient who will have post-operative difficulties, either surgical or anaesthetic in origin. Inevitably, one day the guess will be wrong. The death of a patient outside a recovery ward, from causes which could have been adequately treated in a recovery ward, is a needless disaster. It is not possible to always guess correctly, therefore all patients should pass through the ward to eliminate the need to guess, and also the consequences of an incorrect guess. 


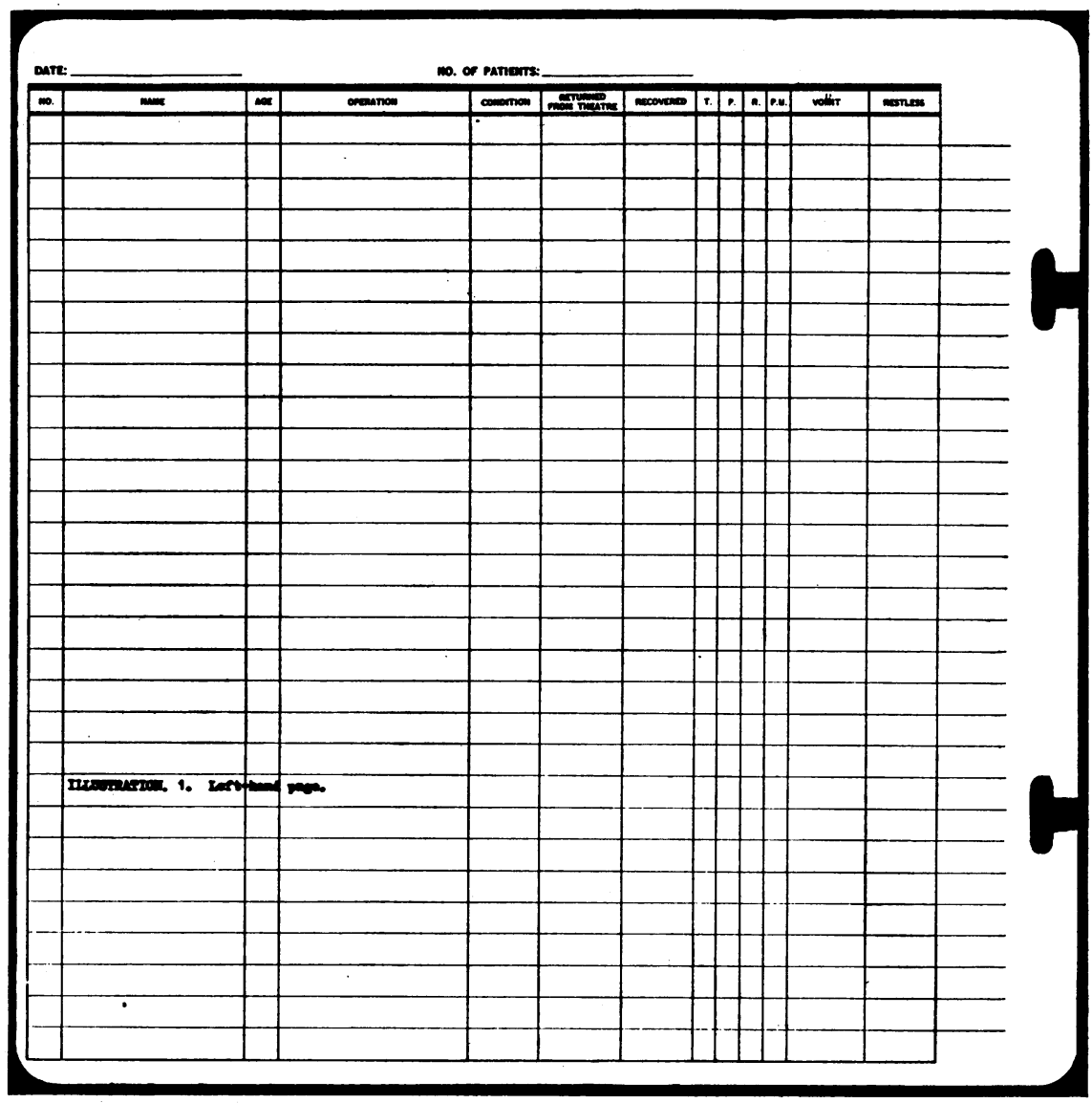

3. The level of nursing skill should be equal to the best in the hospital. A sense of responsibility in the nurse who will constantly supervise the safety of the recovering patient is a prerequisite in the selection of staff. Some nurses make better operating theatre nurses than others; some better surgical ward nurses, and so on. It is clear that some nurses make better recovery ward nurses than others. These we would like to encourage to make this work an important part in their nursing lives. The nursing skill required in a recovery ward is no more 'special' than that required in any other branch of nursing, but it is different. In few other branches of nursing is it possible and necessary to observe a patient from moment to moment and act unerringly, frequently at speed, upon the results of those observations. The required level of nursing skill must be high and, in fact, equal to the highest available in the hospital.

It is probable that nursing staff will be increasingly difficult to secure in adequate numbers. This will be felt earliest and most markedly at provincial non-teaching hospitals. Nevertheless, the recovering patient will still have to be cared for In order to make the most economic use of the nurses available we would suggest that this could best be done by concentrating a proportion of the available talent in a Recovery Ward. It is possible that this shortage has at least been one of the con tributory factors in the rapid adoption and exं pansion of the recovery ward principle in the U.S.A.

4. The nursing staff should never be moved from the ward as a group. Nursing training is most easile and effectively carried out at the bedside. It necessary to have in the ward not only a constant level of ability and knowledge, but also a $\operatorname{con}_{\sqrt{0}}$ tinuous informal clinical training programme. This can best be done by making single staff changes rather than block changes, so that an even leveb of knowledge and skill is maintained in the ward staff. Furthermore, an attempt should be made to retain a trained nurse on the ward staff for a perio $\Phi$ of several months. It is then possible to have an efficient experienced and reliable second-in프 command to the sister. 


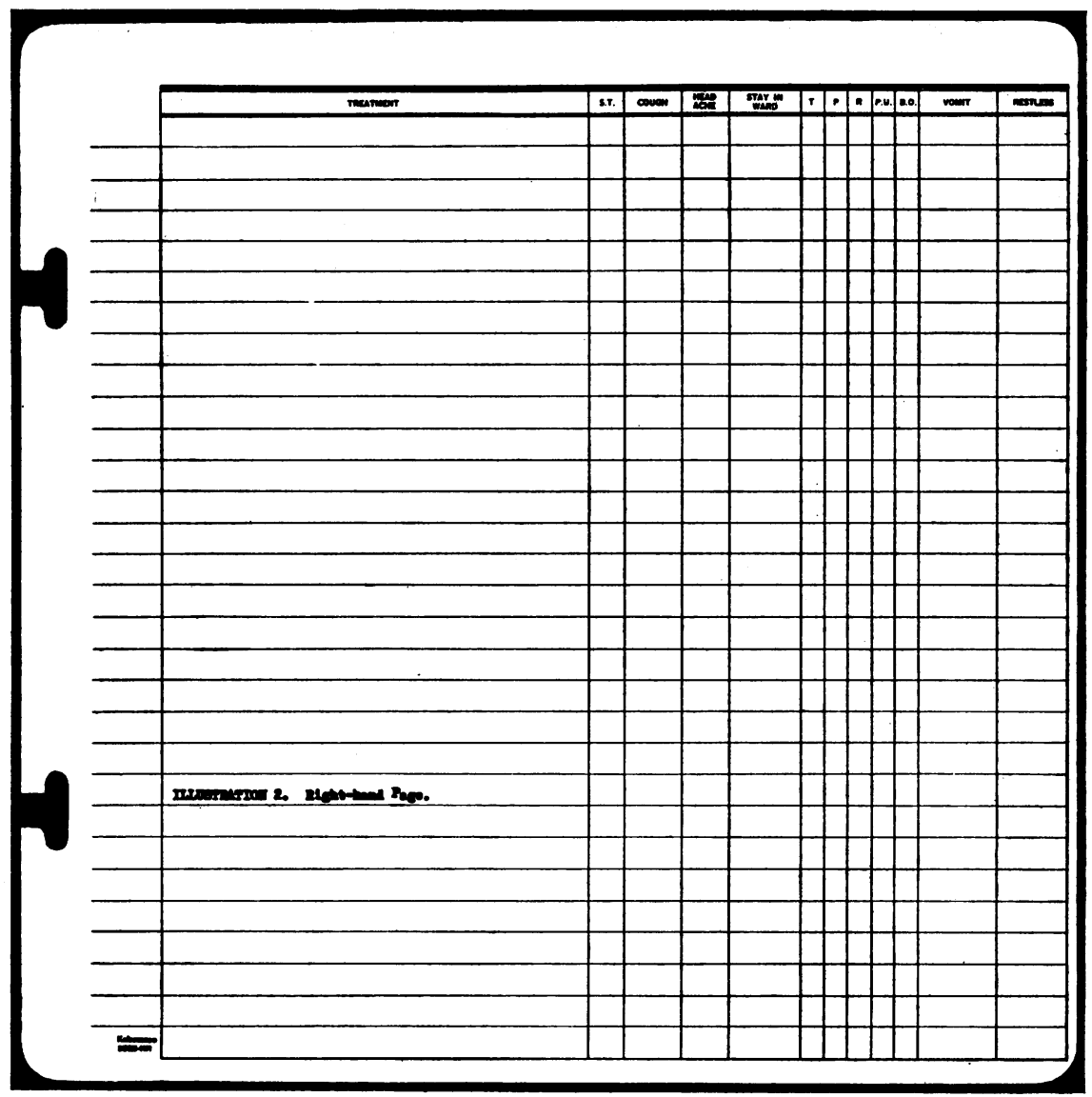

At the present time at Queen Victoria Hospital the staff is as follows:

One male nurse-in-charge (with the status of a departmental sister).

Four staff nurses (S.R.N.), one of whom has been on the ward for a year or more. The other three nurses change more frequently. The second and third at three-monthly intervals and the fourth at six-weekly intervals.

Two ward orderlies.

At night the staff is one S.R.N. and one nursing aid. The former is usually a nurse who has had previous day-time experience of the ward. At times of unusual stress (e.g. emergency admission of a number of severely ill patients) it is accepted that this night staff may have to be augmented at the expense of depleting night ward staff elsewhere in the hospital.

5. The level of record keeping must be high. It must be accurate and detailed. The introduction of a recovery ward involves another link in the chain of care. Information must be received and understood when the patient arrives from the operating theatre; this, with the addition of recovery ward information, must be accurately transmitted when the patient returns to his own ward. This link must be unbreakable.

(a) Records for recovery ward purposes. This will include details of the reception and discharge of the patient, treatment records, drug records, etc. We have found the record illustrated below to be simple yet adequately comprehensive. The appropriate entries are made as the incidents arise and replace the usual ward treatment record and also the admission and discharge records, the T.P.R. records and some drug records.

This chart reduced the secretarial work of the nurse in charge by approximately one-third. The usual report book for passing information from day to night staff is retained. A carbon copy of the day report goes to the matron or deputy at the end of each day's work, for the information of the night sister, who will thus start her night's work with some foreknowledge of the post-operative problems of each patient who has been operated on 
during the day, the majority of whom will still be in the recovery ward.

(b) Patients' records. - It is obviously necessary to ensure that all details of incidents (or lack of them) and of treatment should go with the patient to their own ward. This is most readily done by the sister making the appropriate record in (and not attached to) the patient's notes before departure for their own ward.

6. The recovery ward must be close to the operating theatres. It is our own practice to ensure that the sister of the recovery ward or her deputy goes to the operating theatre to receive the patient from the surgeon and anaesthetist. The recovery ward bed is brought to the operating table side. At the same time instructions on the immediate postoperative care are given. When theatre and the recovery ward are close the surgeon and anaesthetist can make frequent visits to see their patient, and the recovery ward sister can make further visits to the theatre. Close liaison is thus possible.

7. Resuscitative equipment must be adequate to meet all calls made upon it.

8. Medical care must be immediately available in the ward at all times. The senior house officer in anaesthetics holds the same responsibility for this ward as does the house surgeon or house physician to the surgical or medical ward. Frequent visits are made throughout the day by the anaesthetic staff, the majority meeting in the ward at tea-time, a convenient time and place to discuss and view the day's problems. When the house officer is off duty alternative cover is provided by other junior staff. At all times, day or night, a senior member of the anaesthetic staff is available for consultation and call. The nursing staff is kept aware of the whereabouts of those members to whom reference may be made.

9. Retention of the patient for as long as the recovery ward facilities will benefit the patient. This may be short or long. In our experience it has ranged from 20 minutes to 13 days. Only 24 -hour staffing will allow this. The prime consideration is the needs of the patient, not theoretical staffing difficulties.

\section{Discussion}

Upon the above principles much of the success of the ward must stand or fall. Primarily the function of such a ward is to save life. Pask (1955), reporting on an investigation into post-operative deaths which is still being carried out under the auspices of the Association of Anaesthetists of Great Britain and Northern Ireland, stated that there were 700 deaths reviewed. There were $5^{8}$ which appeared to be due to insufficiency of postoperative care. He goes on to state: 'There is absolutely no suggestion of neglect. It means literally that the measures taken did not effectivelog combat adverse influences which arose, but it mas be that no better measures were available.' He found that in 49 the fatal process began as respiratory disturbance, either obstructed respiras tion or inadequate respiratory movements; in 20 cases the patient was found dead, and in eight of those the patient was found dead on arriva in the ward from the operating room; in seve the journey was a long one; in ro cases the in halation of vomitus or blood could clearly be identified as the critical event; there were 19 case 8 following the use of a relaxant, when respiratores insufficiency (other than obstruction) was present. post-operatively; the attendant was an inexperi enced one. From this and other reports it would appear that adequately staffed recovery wards would go a very long way to preventing many these regrettable incidents.

Our own experiences may be summed up thus $s_{+}^{\omega}$ In the 29,388 patients cared for there have beenu many anxious moments. These have occurred often enough for us to feel that any attempt to prophesy which patient would encounter post operative difficulties is fruitless. Nevertheless, of this number of patients, nine have died from alt causes in the post-operative period. Of these nine deaths, we believe one would be classed as avoid able by the investigators of the Association $\mathrm{O}$ Anaesthetists of Great Britain and Northerrmo Ireland. This mortality rate of approximatef I : 3,273 compares with a rate of approximateles I : 1,200 to 1,500 obtaining before the ward was opened.

\section{Secondary Functions}

(a) Economy of staff. It has been stated elsewhere (Davies and Hunter, 1952) that the inclusion of a recovery ward in a hospital leads to no increase in़ि the total number of nursing staff required for the hospital. Of this we are now certain and almost equally certain of the statement which followed it that such a ward may well lead to a reduction in the required number of nursing staff. During a recen period of stringency in nursing staff at this hospita it was agreed with the hospital administration that? in order to maintain the highest possible surgicat turnover with the available staff, the recovery wars. should be the last ward to be denuded of staff not the first. It was interesting to note that during the latter part of this period, despite ward closure and staff shortages, the surgical turnover rose bju approximately 5 per cent.

(b) Economy of equipment. The necessary reo suscitative equipment (oxygen, suction, drip apparatus, etc.) may be concentrated in one area? instead of inadequately spread around the hospitalo

(c) Accuracy of control of medication. Due to the 
possibility of close attention by medical and nursing staff, accurate medication may be 'tailored' in detail to the requirements of the individual patient. One example may suffice:

Number of consecutive cases of induced hypotension (18.10.55 to 3.9.56) $\quad \ldots \quad \ldots \quad \ldots \quad \ldots r, 038$

Number of patients receiving a vasopressor (in all cases methylamphet-

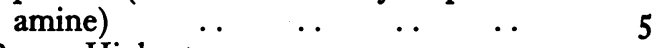

Dose-Highest. . . . $\quad \ldots \quad \ldots \quad$ I 5 mg. Lowest .. . . . . . . 4 mg.

\section{Summary}

As the result of an II-year experience, some principles governing the running of a recovery ward are discussed.

I. Such a ward leads to a decrease in postoperative mortality.

2. No increase in numbers of nursing staff is required.

3. Economies in equipment are possible.
4. Accurate medication of the patient in the post-operative period is more easily possible.

\section{Acknowledgments}

My thanks are due to Mr. C. R. McLaughlin, F.R.C.S.Edin., for his aid in the preparation of this article, to the Matron of the Queen Victoria Hospital for her interest in the recovery ward, and to the nursing staff of the recovery ward for their never-failing interest in our problems.

This article is based in part on a paper read before a Joint Meeting of the Austrian, German and Swiss Anaesthetic Societies in Vienna, June 1957.

\section{BIBLIOGRAPHY}

DAVIES, R. M., and HUNTER, J. T. (1952), Lancet, April 26, 865. LOWENTHAL, P., and RUSSELL, A. S. (1951), Anesthesiology, 12, 470.

MAYO CLINIC SECTION OF ANESTHESIOLOGY (1945), Proc. Mayo Clin., 20, 292.

MAYO CLINIC SECTION OF ANESTHESIOLOGY (1948), Ibid., 23, 301.

MAYO CLINIC SECTION OF ANESTHESIOLOGY (1951), Ibid., 26, 290.

PASK, E. A. (1955), Anaesthesia, ro, 4.

SNOW, J. (1858), 'On Chloroform and other Anaesthetics.'

\section{RHEUMATIC DISORDERS}

(Postgraduate Medical Journal)

Price 3s. 11d. post free

\section{INTRODUCTION: THE RHEUMATIC} DISEASES

F. Dudley Hart, M.D., F.R.C.P.

RECENT ADVANCES IN THE PATHOLOGY OF CHRONIC ARTHRITIS AND RHEUMATIC DISORDERS

D. H. Collins, O.B.E., M.D., M.R.C.P.

\section{RHEUMATOID ARTHRITIS}

J. J. R. DuthIE, F.R.C.P.E.

\section{OSTEOARTHRITIS}

G. C. LLOYD-RoBerTs, M.B., F.R.C.S.
GOUT

R. M. Mason, D.M., M.R.C.P.

THE RARER ARTHROPATHIES

F. DUdley HART, M.D., F.R.C.P.

PHYSICAL METHODS IN THE TREATMENT OF RFEUMATIC DISORDERS

W. S. TrGNER, F.R.C.P.

THE SURGERY OF RHEUMATIC DISEASE

JOHN BASTOW, M.D., F.R.C.S.

THE FELLOWSHIP OF POSTGRADUATE MEDICINE

60, Portland Place, London, W.1 